\author{
Marquette University \\ e-Publications@Marquette
}

School of Dentistry Faculty Research and

Publications

Dentistry, School of

4-2015

\title{
Comparison of Accuracy and Reproducibility of Casts Made by Digital and Conventional Methods
}

\author{
Seok-Hwan Cho \\ Marquette University, seokhwan.cho@marquette.edu \\ Oliver Schaefer \\ Friedrich Schiller University \\ Geoffrey A. Thompson \\ Marquette University, geoffrey.thompson@marquette.edu \\ Arndt Guentsch \\ Marquette University, arndt.guentsch@marquette.edu
}

Follow this and additional works at: https://epublications.marquette.edu/dentistry_fac

Part of the Dentistry Commons

\section{Recommended Citation}

Cho, Seok-Hwan; Schaefer, Oliver; Thompson, Geoffrey A.; and Guentsch, Arndt, "Comparison of Accuracy and Reproducibility of Casts Made by Digital and Conventional Methods" (2015). School of Dentistry Faculty Research and Publications. 115.

https://epublications.marquette.edu/dentistry_fac/115 


\section{Comparison of accuracy and reproducibility of casts made by digital and conventional methods}

Seok-Hwan Cho, DDS, MS

Assistant Professor, Department of General Dental Sciences,

Marquette University School of Dentistry

Milwaukee, WI

Oliver Schaefer, DMD

Assistant Professor, Policlinic of Prosthetic Dentistry and Material

Science, Jena University Hospital, Friedrich Schiller University

Jena, Germany

Geoffrey A. Thompson, DDS, MS

Assistant Professor, Department of General Dental Sciences,

Marquette University School of Dentistry

Milwaukee, WI

Arndt Guentsch, DMD, PhD, MHBA

Associate Professor, Policlinic of Prosthetic Dentistry and Material

Science, Jena University Hospital, Friedrich Schiller University

Jena, Germany

Adjunct Associate Professor, Department of Surgical Science,

Marquette University School of Dentistry

Milwaukee, WI

Journal of Prosthetic Dentistry, Vol. 113, No. 4 (April 2015): pg. 310-315. DOI. This article is @ Elsevier and permission has been granted for this version to appear in e-Publications@Marquette. Elsevier does not grant permission for this article to be further copied/distributed or hosted elsewhere without the express permission from Elsevier. 
NOT THE PUBLISHED VERSION; this is the author's final, peer-reviewed manuscript. The published version may be accessed by following the link in the citation at the bottom of the page.

\section{Abstract:}

Statement of problem. Little peer-reviewed information is available regarding the accuracy and reproducibility of digitally fabricated casts in comparison with conventional nondigital methods.

Purpose. The purpose of this in vitro study was to compare the accuracy and reproducibility of a digital impression and cast fabrication with a conventional impression and cast fabrication.

Material and Methods. Conventional impressions were made via a one-step single viscosity (OS/SV) technique with vinyl siloxanether material of a typodont master model, and conventional casts were cast from dental stone. Digital impressions were obtained with a digital scanner, and digital SLA models were printed. The typodont and fabricated casts were digitized with a structured light scanner and saved in surface tessellation language (STL) format. All STL records were superimposed via a best-fit method. The digital impression and cast fabrication method was compared with the conventional impression and cast fabrication method for discrepancy, accuracy, and reproducibility. The Levene test was used to determine equality of variances and a 1-way analysis of variance (ANOVA) was conducted to assess the overall statistical significance of differences among the groups $(n=5, a=.05)$.

Results. No significant statistical difference was found between the digital cast and conventional casts in the internal area or finish line area $(P>.05)$. In addition, there was no statistically significant difference between these 2 techniques for a fixed dental prosthesis or single crown $(P>.05)$. However, statistically significant differences were observed for overall areas of the casts, in terms of accuracy $(P<.01)$ and reproducibility $(P<.001)$. Digital impression and cast fabrication were less accurate and reproducible than conventional impression and cast fabrication methods.

Conclusions. No statistically significant difference was found between the digital cast and conventional cast groups in the internal and finish line areas. However, in terms of the reproducibility and accuracy of the entire cast area, the conventional cast was significantly better than the digital cast.

Clinical implication. Digital impression and cast fabrication methods are becoming increasingly more accurate, but their shortcomings in accuracy and reproducibility mean they may not yet adequately replace conventional impression and cast fabrication.

Journal of Prosthetic Dentistry, Vol. 113, No. 4 (April 2015): pg. 310-315. DOI. This article is @ Elsevier and permission has been granted for this version to appear in e-Publications@Marquette. Elsevier does not grant permission for this article to be further copied/distributed or hosted elsewhere without the express permission from Elsevier. 
NOT THE PUBLISHED VERSION; this is the author's final, peer-reviewed manuscript. The published version may be accessed by following the link in the citation at the bottom of the page.

\section{INTRODUCTION}

Accurate and precise replicas of the teeth are essential for producing prosthetic restorations with accurate internal and marginal adaptation. The impression technique is a significant factor in this context. ${ }^{1}$ Currently, 2 options are available for making impressions of dental arches: digital impression using intraoral scanners to generate a digital dataset, or conventional impressions using elastomeric impression materials. Elastomeric impression materials have been extensively investigated. Studied variables include material and tray selection, ${ }^{2}$ impression technique, ${ }^{3}$ rheological properties, ${ }^{4}$ and position and curvature of preparation finish lines. ${ }^{5}$ Since poor quality impressions can compromise the quality of restorations, ${ }^{6}$ detailed information on appropriate impression techniques is required for longterm clinical success.

There is evidence that polyether impressions should be poured only once and within 24 hours after impression making because of the gradual distortion of the material. 7,8 Polyvinyl siloxane impression material has been reported to have better dimensional stability than polyether. ${ }^{9}$ However, vinyl siloxanether material has been shown to have better dimensional accuracy than either polyether or polyvinyl siloxane. ${ }^{9,10}$ Although the setting expansion of contemporary Type IV die stones is intended to match the polymerization shrinkage of vinyl siloxanether elastomeric impression materials, ${ }^{11}$ working cast dimensions have been shown to be oversized when compared to the original tooth. ${ }^{10}$

Recently, equipment (Lava C.O.S.; 3M ESPE) has been introduced that uses advanced imaging technology to produce a digital impression of the dental arch, which is then translated into a 3dimensional (3D) stereolithographic (SLA) cast. A study of digital impression making reported that the accuracy of the digital impressions was similar to that of the conventional impression. ${ }^{12}$ The precision and accuracy of the new method were described as being comparable with conventional impression making and stone cast fabrication when executed by trained dental professionals. ${ }^{13}$ Furthermore, digital casts are becoming the standard in orthodontic treatment. ${ }^{14,15}$

Journal of Prosthetic Dentistry, Vol. 113, No. 4 (April 2015): pg. 310-315. DOI. This article is (C) Elsevier and permission has been granted for this version to appear in e-Publications@Marquette. Elsevier does not grant permission for this article to be further copied/distributed or hosted elsewhere without the express permission from Elsevier. 
Currently, few studies are available assessing the accuracy of casts produced by digital scans. ${ }^{16-18}$ A recently introduced method allows the quantitative and qualitative 3D analysis of dental materials, including restorations, impressions, or casts. ${ }^{19}$ The aim of this study was to identify the discrepancy, accuracy, and reproducibility of digital casts compared with a master model. Discrepancy was defined as the dimensional differences of the superimposed values between both casts to the control (master typodont standard). Accuracy was described as how close the data were to the master typodont standard, and reproducibility examined the consistency of the casts to each other. The null hypothesis was that no significant difference would be found between these 2 methods.

\section{MATERIAL AND METHODS}

A maxillary typodont model (standard working model AG-3; Frasaco $\mathrm{GmbH}$ ) with a complete dentition and 5 prepared teeth (right maxillary first molar, right maxillary second premolar, left maxillary central incisor, left maxillary canine, and left first molar) served as the master model. One-step single viscosity (OS/SV) impressions were made with a vinyl siloxanether material (Identium medium; Kettenbach $\mathrm{GmbH}$ ), following the manufacturer's instructions. All impressions were made under standard laboratory conditions $\left(22^{\circ} \mathrm{C}\right)$ by a single investigator (OS).

A power analysis was conducted to estimate the required sample size; 6 specimens ( 3 per group) were required, assuming 4 test groups, an effect size of 4.49, type I error probabilities of .05, and type II error probabilities of .95. Thus, sample size was determined with $n=5$ per group. The typodont was mounted on a rectangular base containing 3 conical guide pins to allow for reproducible tray positioning. Adhesive (Identium Adhesive; Kettenbach $\mathrm{GmbH}$ ) was applied to aluminum-made customized trays, with 5 brushstrokes (approximately $0.2 \mathrm{~mL}$ per tray). Five impressions were made from the typodont. To ensure adequate polymerization at room temperature, all impressions were allowed to set 3 times longer (10 minutes) than recommended by the manufacturer. ${ }^{20}$ The design of the custom tray ensured an even material thickness of $3 \mathrm{~mm}$ around the prepared teeth once the impression tray was inserted. ${ }^{21}$ 
NOT THE PUBLISHED VERSION; this is the author's final, peer-reviewed manuscript. The published version may be accessed by following the link in the citation at the bottom of the page.

After removal, impressions were inspected for defects and treated with 3 spray bursts (approximately $0.5 \mathrm{~mL}$ ) of surfactant (Debubblizer Surfactant; Almore International Inc) to reduce surface tension and improve the quality of the resulting cast. ${ }^{22}$ The impression surface was blown dry and poured with Type IV dental stone (Tewerock; Kettenbach $\mathrm{GmbH})$. Distilled water $(20 \mathrm{~mL})$ and gypsum powder $(100 \mathrm{~g})$ were vacuum mixed for 45 seconds (Wamix-Classic; Wassermann Dental-Maschinen $\mathrm{GmbH}$ ) and vibrated (KV-16; Wassermann Dental-Maschinen $\mathrm{GmbH}$ ) into the impressions. Casts were allowed to set for 45 minutes before removal and inspection.

The digital impressions were made 5 times by a single trained investigator (SC) with a digital scanner (Lava Chairside Oral Scanner; 3M ESPE). The typodont was fixed in a simulated patient position on a phantom head. After the digital data were captured, the data files were saved, copied, and sent to an authorized Lava manufacturing center for SLA model production.

The typodont and the fabricated casts were digitized with a structured light scanner developed by the Fraunhofer Institute for Applied Optics and Precision Engineering IOF (Flex 3A; Otto Vision Technology $\mathrm{GmbH}$ ), featuring a measurement-uncertainty of $<5 \mu \mathrm{m}$ and a homogenous measuring-point-distance of $5 \mu \mathrm{m}$ (data according to manufacturer). Datasets for cast and the reference typodont were computed (Qualify 12; Geomagic $\mathrm{GmbH}$ ) and saved in a surface tessellation language (STL), standard for computer-aided design and computer-aided manufacturing (CAD/CAM) data exchange format. STL records of the typodont and casts were superimposed one on the other by computing all possible orientations and selecting the one with the best object-to-object penetration (best-fit-method). ${ }^{23}$

By computing all possible orientations (Qualify 12, Geomagic $\mathrm{GmbH}$ ), records of SLA and conventional casts were superimposed. With this superimposition, the SLA and conventional casts data were represented by the averages of all casts in their given type to represent the best object-to-object penetration. Dimensional differences between both casts to the typodont were computed. Thereby, the mean deviation root mean square (RMS) of the virtual reference object in comparison with the test objects was used to estimate the congruency of 2 superimposed records by the formula ${ }^{19}$

Journal of Prosthetic Dentistry, Vol. 113, No. 4 (April 2015): pg. 310-315. DOI. This article is @ Elsevier and permission has been granted for this version to appear in e-Publications@Marquette. Elsevier does not grant permission for this article to be further copied/distributed or hosted elsewhere without the express permission from Elsevier. 
NOT THE PUBLISHED VERSION; this is the author's final, peer-reviewed manuscript. The published version may be accessed by following the link in the citation at the bottom of the page.

$R M S=\frac{1}{\sqrt{n}} \cdot \sqrt{\sum_{i=1}^{n}\left(x_{1, i}-x_{2, i}\right)^{2}}$, where $\mathrm{x}_{1, \mathrm{i}}$ is measuring point $\mathrm{i}$ on reference, $\mathrm{x}_{2, \mathrm{i}}$ is measuring point $\mathrm{i}$ on duplicate, and $\mathrm{n}$ is total number of measuring points per specimen. RMS values were calculated only for the teeth area, not for any gingival areas.

All statistical computations were made with statistical software (IBM SPSS Statistics 21; IBM SPSS Inc). Means (RMS), standard deviations, and 95\% confidence intervals were calculated for marginal and internal discrepancies, accuracy, and precision. The Levene test was performed to verify departures from basic assumptions about variance and normality. A 1-way analysis of variance (ANOVA) was conducted to assess the overall statistical significance of differences among the groups $(a=.05)$.

\section{RESULTS}

Table I describes the values of discrepancies in both the internal area and finish line area of the 2 groups. For a finish line area, digital casts offered slightly smaller discrepancy value (10 $\pm 0 \mu \mathrm{m})$ in comparison with the conventional cast group counterparts (12 $\pm 4 \mu \mathrm{m})$. In terms of internal area, conventional casts offered slightly smaller values of discrepancy (16 $\pm 3 \mu \mathrm{m})$ in comparison with the digital cast group (21 $\pm 4 \mu \mathrm{m})$. Despite these differences in discrepancies, no significant statistical difference was found between digital and conventional casts (finish line: $\mathrm{T}=-1.40, \mathrm{df}=8, P=.201$; internal: $\mathrm{T}$ $=1.98, \mathrm{df}=8, P=.084)$.

Table II describes the values of discrepancies in a fixed dental prosthesis (FDP) and a single crown of the 2 groups. The conventional cast group exhibited the discrepancy value of $57 \pm 5 \mu \mathrm{m}$ (FDP) and 14 $\pm 4 \mu \mathrm{m}$ (single crown). In contrast, the digital cast group showed the discrepancy ranges of $67 \pm 8 \mu \mathrm{m}$ (FDP) and $21 \pm 5 \mu \mathrm{m}$ (single crown). Even though a statistically significant difference was found between the 2 situations, FDP and single crown, within the group, there was no statistical significant difference between these 2 groups in 2 different situations (FDP: $\mathrm{T}=2.369, \mathrm{df}=8, P=.052$; Crown: $\mathrm{T}=2.322$, $\mathrm{df}=$ $8, P=.052)$.

Journal of Prosthetic Dentistry, Vol. 113, No. 4 (April 2015): pg. 310-315. DOI. This article is @ Elsevier and permission has been granted for this version to appear in e-Publications@Marquette. Elsevier does not grant permission for this article to be further copied/distributed or hosted elsewhere without the express permission from Elsevier. 
NOT THE PUBLISHED VERSION; this is the author's final, peer-reviewed manuscript. The published version may be accessed by following the link in the citation at the bottom of the page.

Table III describes the accuracy and reproducibility of digital and conventional casts for the whole cast areas. Statistically significant differences were found in the accuracy and reproducibility of the 2 groups; with the means of $11 \pm 3 \mu \mathrm{m}$ in accuracy and $54 \pm 6 \mu \mathrm{m}$ in reproducibility, the conventional casts group showed smaller discrepancy values than those of the digital cast group, which had means of $27 \pm 7 \mu \mathrm{m}$ in accuracy and $91 \pm 10 \mu \mathrm{m}$ in reproducibility (accuracy: $\mathrm{T}=1.507, \mathrm{df}=7, P<.001$; reproducibility: $\mathrm{T}=7.24$, $\mathrm{df}=$ $8, P<.001)$.

Figures 1 and 2 depict the individual preparation and complete arch representations for both conventional and digital impression methods in the STL format. For the individual preparation, recorded discrepancies ranged from $-150 \mu \mathrm{m}$ (navy blue) to $150 \mu \mathrm{m}$ (red), whereas for the complete arch, discrepancies ranged from $-500 \mu \mathrm{m}$ (navy blue) to $500 \mu \mathrm{m}$ (red). Negative discrepancies (light blue to navy blue) represent smaller size in comparison with the typodont standard. Positive discrepancies (red to yellow) represent larger size in comparison with the typodont standard. Acceptable discrepancies ( -5 $\mu \mathrm{m}$ to $5 \mu \mathrm{m}$, for individual preparation and or $-50 \mu \mathrm{m}$ to $50 \mu \mathrm{m}$ for complete arch representations) are shown as green. Figures 3 depicts the posterior single crown and FDP preparation representations for both conventional and digital impression methods in the STL format. Figure 4 demonstrates the anterior FDP preparation representations.

For both the conventional and digital impression methods, the recorded axial and occlusal discrepancies ranged from $-41 \mu \mathrm{m}$ (light blue) to $59 \mu \mathrm{m}$ (red to yellow) for premolar preparations (Fig. 1) and $75 \mu \mathrm{m}$ (light blue) to $125 \mu \mathrm{m}$ (red to yellow) for FDPs (Figs. 2-4). However, the areas of underrepresentation and overrepresentation were different for these 2 methods. The red-colored pontic area may have been an artifact and was not further evaluated.

\section{DISCUSSION}

The present study investigated the accuracy and reproducibility of casts made by digital and conventional impression and cast fabrication methods. For the complete arch comparison, a statistically significant difference was found between the 2 methods in terms of accuracy and reproducibility. Compared with digital impression and

Journal of Prosthetic Dentistry, Vol. 113, No. 4 (April 2015): pg. 310-315. DOI. This article is (C Elsevier and permission has been granted for this version to appear in e-Publications@Marquette. Elsevier does not grant permission for this article to be further copied/distributed or hosted elsewhere without the express permission from Elsevier. 
cast fabrication methods, conventional impression and cast fabrication methods remain more accurate and reproducible. Conventional cast fabrication using custom tray and dimensionally stable impression material offered a more reliable representation of the original dental complete arch in comparison with digital cast fabrication. The less accurate casts made by digital methods may require additional intraoral adjustment of the occlusal and proximal areas because of the inaccurate mounting and dimensional change.

However, a comparison of the prepared teeth area showed no statistically significant difference between the 2 methods (Table I). In other words, the digital method is compatible with conventional methods in terms of prepared teeth surface accuracy. Since prepared teeth surface accuracy is critical for fitting of fixed prosthodontic restorations, digital impression and cast fabrication could be a useful methodt for achieving adequate internal fit and marginal gap. Kim et al $^{16}$ reported different results in their study, which used an iTero, Parallel Confocal Imaging system. The study showed that working dies made by conventional impression methods were significantly more accurate than those obtained through digital impression. However, no significant difference was found in accuracy on the marginal form areas of the dies. The differences in the current results may be attributed to the use of different conventional impression materials and procedures and to different digital impression methods. Guth et $\mathrm{al}^{17}$ reported that the intraoral Lava C.O.S system showed significantly higher accuracy than the conventional impression procedure and indirect digitalization. However, intraoral conditions such as saliva, powder, and limited space could contribute to inaccuracies in the digital scan. ${ }^{16,18}$

The quality of digital and conventional methods has also been investigated. In Figure 1 (premolar tooth), both conventional and digital impression and cast fabrication methods exhibited underrepresentation (negative value) of the buccal walls, which can require adjustment before cementation. However, both methods presented overrepresentation (positive value) of the mesial, distal, and lingual surfaces, which can cause looseness of the restorations. Overall, on the middle area of the occlusal surface, conventional method casts showed more underrepresentation (blue) than digital method casts, which demonstrated slight overrepresentation (yellow) 
on that area. However, Figures 4 and 5 show the molar and anterior tooth preparation areas with a similar distribution of colors.

This study has several limitations in terms of chemical composition, light reflection, and the surface morphology of natural teeth. First, the present study used a typodont for patient simulation, which is different from a real patient's oral cavity and natural tooth condition. The typodont acrylic teeth can eliminate the effect of saliva, temperature-related distortion, or water resorption during storage. In addition, this study used only 1 conventional impression material and 1 digital impression system, and, general conclusions should be carefully drawn. Further research with different materials and systems will be necessary to validate the present results.

\section{CONCLUSION}

Compared with digital impression and cast fabrication methods, conventional impression and cast fabrication methods showed the statistically superior accuracy and reproducibility of complete arch casts. However, in terms of the prepared teeth area, no statistically significant difference could be found between the 2 methods.

\section{REFERENCES}

1. Persson ASK, Andersson M, Oden A, Sandborgh-Englund G. Computer aided analysis of digitized dental stone replicas by dental CAD/CAM technology. Dent Mater 2008;24:1123-30.

2. Johnson GH, Mancl LA, Schwedhelm ER, Verhoef DR, Lepe X. Clinical trial investigating success rates for polyether and vinyl polysiloxane impressions made with full-arch and dual-arch plastic trays. J Prosthet Dent 2010;103:13-22.

3. Kwon JH, Son $\mathrm{YH}$, Han $\mathrm{CH}$, Kim S. Accuracy of implant impressions without impression copings: A three-dimensional analysis. J Prosthet Dent 2011;105:367-73.

4. Berg JC, Johnson GH, Lepe X, Adan-Plaza S. Temperature effects on the rheological properties of current polyether and polysiloxane impression materials during setting. J Prosthet Dent 2003;90:150-61.

5. Luthardt RG, Walter MH, Weber A, Koch R, Rudolph $\mathrm{H}$. Clinical parameters influencing the accuracy of 1 - and 2-stage impressions: A randomized controlled trial. Int J Prosthodont 2008;21:322-27.

Journal of Prosthetic Dentistry, Vol. 113, No. 4 (April 2015): pg. 310-315. DOI. This article is (C Elsevier and permission has been granted for this version to appear in e-Publications@Marquette. Elsevier does not grant permission for this article to be further copied/distributed or hosted elsewhere without the express permission from Elsevier. 
NOT THE PUBLISHED VERSION; this is the author's final, peer-reviewed manuscript. The published version may be accessed by following the link in the citation at the bottom of the page.

6. Reich S, Gozdowski S, Trentzsch L, Frankenberger R, Lohbauer U. Marginal fit of heat-pressed vs. CAD/CAM processed all-ceramic onlays using a milling unit prototype. Oper Dent 2008;33:644-50.

7. Nassar U, Oko A, Adeeb S, El-Rich M, Flores-Mir C. An in vitro study on the dimensional stability of a vinyl polyether silicone impression material over a prolonged storage period. J Prosthet Dent. 2013;109:172-8.

8. Gomez-Polo M, Celemin A, del Rio J, Sanchez A. Influence of technique and pouring time on dimensional stability of polyvinyl siloxane and polyether impressions. Int J Prosthodont. 2012;25:353-6.

9. Thongthammachat S, Moore BK, Barco MT, Hovijitra S, Brown DT, Andres C]. Dimensional accuracy of dental casts: Influence of tray material, impression material, and time. J Prosthodont 2002:98-108.

10. Stober T, Johnson GH, Schmitter M. Accuracy of the newly formulated vinyl siloxanether elastomeric impression material. J Prosthet Dent 2010;103:228-39.

11. Schaefer O, Schmidt M, Goebel R, Kuepper H. Qualitative and quantitative three-dimensional accuracy of a single tooth captured by elastomeric impression materials: an in vitro study. J Prosthet Dent. 2012;108:165-72.

12. Ender A, Mehl A. Full arch scans: conventional versus digital impressions: An in-vitro study. Int J Comput Dent 2011;14:11-21.

13. Jäger K, Vögtlin C. Digital workflow with the chair-side oral scanner C.O.S and Lava-technology. Schweiz Monatsschr Zahnmed 2012;122:30715.

14. Keating AP, Knox J, Bibb R, Zhurov AI. A comparison of plaster, digital and reconstructed study model accuracy. J Orthod 2008;35:191-201; discussion 175 .

15. Alcan T, Ceylanoğlu C, Baysal B. The relationship between digital model accuracy and time-dependent deformation of alginate impressions. Angle Orthodont 2009;79:30-6.

16. Kim SY, Kim MJ, Han JS. Acuracy of dies captured by an intraoral digital impression system using parallel confocal imaging. Int J Prosthodont 2013;26:161-63.

17. Guth J, Kuel C, Stimmelmayr M, Beuer F. Accuracy of digital models obtained by direct and indirect data capturing. Clin Oral Invest 2013;17:1201-08.

18. Flugge T, Schlager S, Nelson K, Nahles S, Metzger M. Precision of intraoral digital dental impressions with iTero and extraoral digitization

Journal of Prosthetic Dentistry, Vol. 113, No. 4 (April 2015): pg. 310-315. DOI. This article is @ Elsevier and permission has been granted for this version to appear in e-Publications@Marquette. Elsevier does not grant permission for this article to be further copied/distributed or hosted elsewhere without the express permission from Elsevier. 
NOT THE PUBLISHED VERSION; this is the author's final, peer-reviewed manuscript. The published version may be accessed by following the link in the citation at the bottom of the page.

with the iTero and a model scanner. Am I Orthod Dentofacial Orthop 2013;144:471-8.

19. Schaefer O, Watts DC, Sigusch BW, Kuepper H, Guentsch A. Marginal and internal fit of pressed lithium disilicate partial crowns in vitro: A threedimensional analysis of accuracy and reproducibility. Dent Mater 2012;28:320-26.

20. Wadhwani CP, Johnson GH, Lepe X, Raigrodski AJ. Accuracy of newly formulated fast-setting elastomeric impression materials. J Prosthet Dent 2005;93:530-9.

21. Valderhaug J, Floystrand F. Dimensional stability of elastomeric impression materials in custom-made and stock trays. J Prosthet Dent $1984 ; 52: 514-7$.

22. Millar BJ, Dunne SM, Robinson PB. The effect of a surface wetting agent on void formation in impressions. J Prosthet Dent 1997;77:54-6.

23. Luthardt RG, Koch R, Rudolph $\mathrm{H}$, Walter $\mathrm{MH}$. Qualitative computer aided evaluation of dental impressions in vivo. Dent Mater 2006;22:69-76.

\section{About the Authors}

Dr Seok-Hwan Cho: Department of General Dental Sciences, Prosthodontics, Marquette University School of Dentistry, PO Box 1881, Milwaukee, WI 53201-1881

Email: seokhwan.cho@marquette.edu 
NOT THE PUBLISHED VERSION; this is the author's final, peer-reviewed manuscript. The published version may be accessed by following the link in the citation at the bottom of the page.

Table I. Mean (SD) RMS-values and 95\% confidence intervals [95\%-CI] in $\mu \mathrm{m}$ for internal area and finish line area discrepancies of prepared teeth.

Internal area

Finish line area

\begin{tabular}{lccccccc}
\cline { 2 - 3 } \cline { 5 - 7 } RMS in $\mu \mathrm{m}$ & Mean & $(\mathrm{SD})$ & {$[95 \%-\mathrm{CI}]$} & & Mean & $(\mathrm{SD})$ & {$[95 \%-\mathrm{CI}]$} \\
\hline Digital & 22 & $(5)$ & {$[16-27]$} & & 10 & $(0)$ & {$[10-10]$} \\
Conventional & 17 & $(3)$ & {$[13-21]$} & & 12 & $(4)$ & {$[8-17]$} \\
\hline
\end{tabular}

No statistically significant differences within or between groups.

Table II. Discrepancies of prepared teeth in fixed dental prosthesis (FDP) and single crown situation. Comparison of digital and conventional casts with master model (typodont). Means, standard deviation (SD), and 95\% confidence intervals [95\%-CI] from $n=5$ are given in $\mu \mathrm{m}$.

FDP

Single Crown

\begin{tabular}{lccccccc}
\cline { 2 - 3 } \cline { 6 - 7 } RMS in $\mu \mathrm{m}$ & Mean & $(\mathrm{SD})$ & {$[95 \%-\mathrm{CI}]$} & & Mean & $(\mathrm{SD})$ & {$[95 \%-\mathrm{CI}]$} \\
\hline Digital & 67 & $(8)$ & {$[57-63]$} & & $21^{\S}$ & $(5)$ & {$[14-27]$} \\
Conventional & 57 & $(5)$ & {$[51-63]$} & & $14 \S$ & $(4)$ & {$[10-19]$} \\
\hline
\end{tabular}

No statistical differences between groups of digital and conventional casts. Statistically significant differences were found within group between FDP and single crown situation $(P<.01)^{\S}$

Journal of Prosthetic Dentistry, Vol. 113, No. 4 (April 2015): pg. 310-315. DOI. This article is @ Elsevier and permission has been granted for this version to appear in e-Publications@Marquette. Elsevier does not grant permission for this article to be further copied/distributed or hosted elsewhere without the express permission from Elsevier. 
NOT THE PUBLISHED VERSION; this is the author's final, peer-reviewed manuscript. The published version may be accessed by following the link in the citation at the bottom of the page.

Table III. Accuracy and reproducibility of digital and conventional casts for complete arch. Means, standard deviation (SD), and 95\% confidence intervals [95\%CI] from $n=5$ are given in $\mu \mathrm{m}$.

Accuracy Reproducibilty

\begin{tabular}{lccccccc}
\cline { 2 - 4 } \cline { 6 - 7 } RMS in $\mu \mathrm{m}$ & Mean & (SD) & {$[95 \%-\mathrm{CI}]$} & & Mean & $(\mathrm{SD})$ & {$[95 \%-\mathrm{CI}]$} \\
\hline Digital & 27 & $(7)$ & {$[5-38]$} & & 91 & $(10)$ & {$[79-104]$} \\
Conventional & $11^{*}$ & $(3)$ & {$[7-15]$} & & $54^{\#}$ & $(6)$ & {$[47-62]$} \\
\hline
\end{tabular}

For accuracy, statiscally significant difference exist between groups of digital and conventional casts. $(P<.01)^{*}$

For reproducibility, statistically significant difference exists between groups of digital and conventional casts $(P<.001)^{\#}$.

\section{LEGENDS}

Fig. 1. Qualitative analysis of internal and finish line area on premolar tooth preparation. A, Digital method. B, Conventional method. C, Deviations from reference tooth presented as color codes.

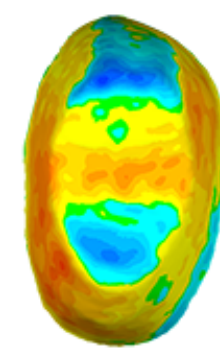

A.

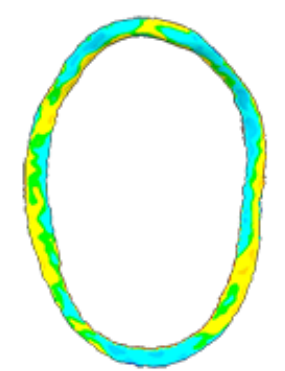

$\vdots$
$\vdots$
$\vdots$
$\vdots$
$\vdots$
$\vdots$

C.

Journal of Prosthetic Dentistry, Vol. 113, No. 4 (April 2015): pg. 310-315. DOI. This article is (C) Elsevier and permission has been granted for this version to appear in e-Publications@Marquette. Elsevier does not grant permission for this article to be further copied/distributed or hosted elsewhere without the express permission from Elsevier.
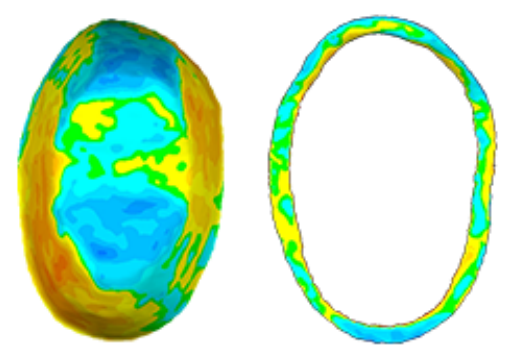

B. 
NOT THE PUBLISHED VERSION; this is the author's final, peer-reviewed manuscript. The published version may be accessed by following the link in the citation at the bottom of the page.

Fig. 2. Qualitative analysis of complete arch situation. A. Digital method, B. Conventional method, C. Deviations measured from reference model.

A.

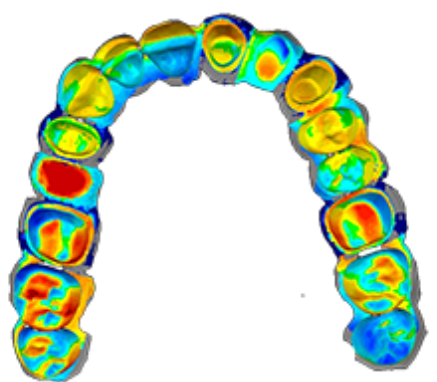

B.

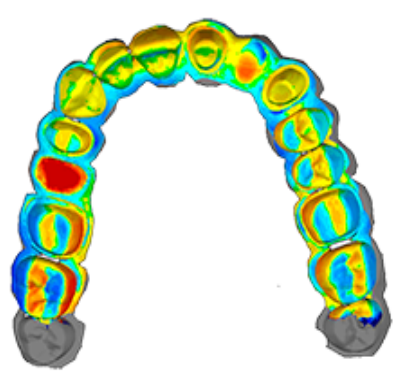

C.

Fig. 3. Color coded images of each single crown preparation on molars and fixed dental prosthesis preparation of posterior areas. A, Digital method. B, Conventional method
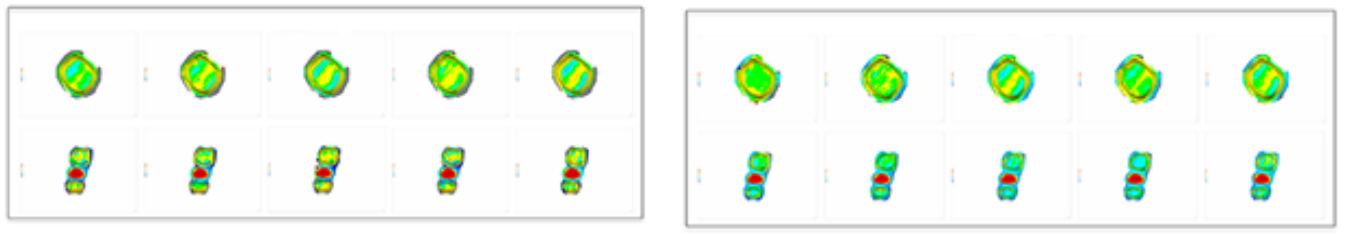

A.

B.

Journal of Prosthetic Dentistry, Vol. 113, No. 4 (April 2015): pg. 310-315. DOI. This article is @ Elsevier and permission has been granted for this version to appear in e-Publications@Marquette. Elsevier does not grant permission for this article to be further copied/distributed or hosted elsewhere without the express permission from Elsevier. 
NOT THE PUBLISHED VERSION; this is the author's final, peer-reviewed manuscript. The published version may be accessed by following the link in the citation at the bottom of the page.

Fig. 4. Qualitative analysis of anterior fixed dental prosthesis preparation. A, Digital method. B, Conventional method
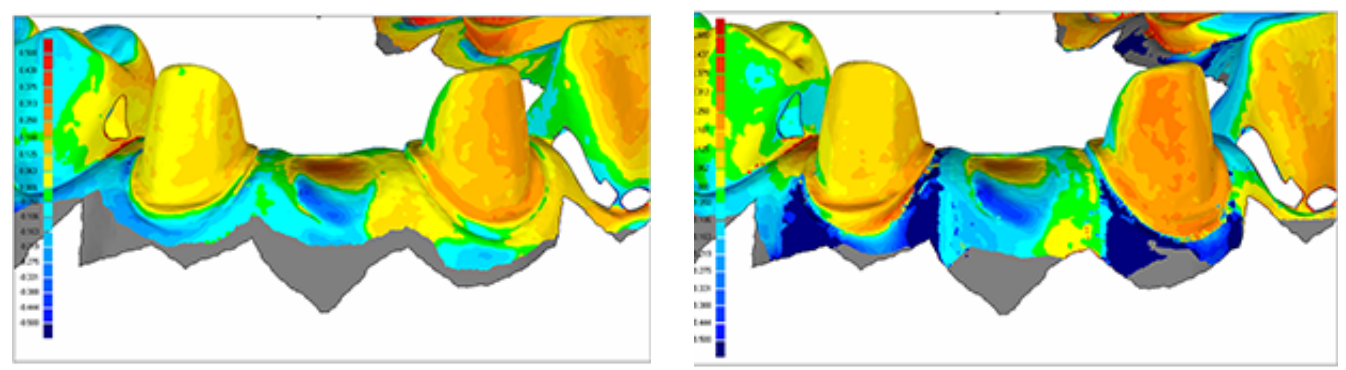

A.

B.

Journal of Prosthetic Dentistry, Vol. 113, No. 4 (April 2015): pg. 310-315. DOI. This article is @ Elsevier and permission has been granted for this version to appear in e-Publications@Marquette. Elsevier does not grant permission for this article to be further copied/distributed or hosted elsewhere without the express permission from Elsevier. 